\title{
Integrative Oncology: Hope or Hype?
}

\author{
Taiebeh Taheripanah, ${ }^{1}$ Mahdi Sardari, ${ }^{2}$ and Hossein Rezaeizadeh ${ }^{2 *}$ \\ Radiation Oncologist, Besat Hospital, AJA University of Medical Sciences, Tehran, IR Iran \\ ${ }^{2}$ Department of Traditional Medicine, Persian Medicine and Pharmacy Research Center, School of Traditional Medicine, Tehran University of Medical Sciences, \\ Tehran, IR Iran \\ *Corresponding author: Hossein Rezaeizadeh, Department of Traditional Medicine, Persian Medicine and Pharmacy Research Center, School of Traditional \\ Medicine, Tehran University of Medical Sciences, Tehran, IR Iran. Tel: +98-9127038842, Fax:+98-21-66917678, E-mail: rezaeizadeh@sina.tums.ac.ir \\ Received: April 1, 2015; Accepted: May 29, 2015
}

\begin{abstract}
Context: According to Association of Academic Health Centers definition, integrative medicine is as a healing-oriented approach of medicine that takes account of the whole person, including all aspects of lifestyle by employing both conventional and unconventional as traditional or complementary and alternative medicine to achieve the best treatment and recovery which is the focus of the present study.

Evidence Acquisition: Main oncology resources pointing to complementary and alternative medicine (CAM) modalities in cancer care, evidence-based articles, data obtained from integrative oncology clinics and government organizations associated with cancer were the materials used in this study.

Results: Studies indicate the growing trend in using CAM worldwide. Generally, 38\% of adults and 12\% of children use CAM in United States referring national researches in 2007; however, other studies show 83 to 92 percent of cancer patient have made use of it. Most complementary modalities are noninvasive and useful in reducing symptoms and side effects of conventional treatments and improving quality of life. Some high quality scientific research has produced evidence that acupuncture, massage, music, and mind-body therapies effectively and safely reduce physical and emotional affects. Integrative oncology relates to an emerging conversation between CAM scholars, oncology care professionals, and family practitioners imagining a holistic patient-centered approach to oncology care.

Conclusions: An increasing recognition in health care systems has emerged, especially in oncology of the importance of maintaining or improving patients' quality of life all over the disease course. Cancer patients with lower quality of life are more likely to terminate therapy so this should be as an alarm to oncologist the risk for not completing therapy. Complementary methods have played a significant role in this situation for enhancing quality of life, reduced severity of symptoms and side effects, and developed general wellbeing in patients.
\end{abstract}

Keywords: Integrative Medicine; Cancer

\section{Context}

Integrative medicine is a newfound approach and exquisite thinking in the arena of medicine which is developing in different disciplines of medicine. Association of Academic Health Centers defines integrative medicine in this way: a healing-oriented approach of medicine that takes account of the whole person, including all aspects of lifestyle. It emphasizes the importance of relationship between the physician and the patient and makes use of all appropriate therapies, both conventional and unconventional as traditional or complementary and alternative medicine to achieve the best treatment and recovery. Integrative oncology is the first developed system in this background and provides a comprehensive care system for cancer patients at every stage of treatment and level of clinical condition.

Integrative oncology departments use evidenced-based complementary interventions to promote the mainstream care by controlling the serious physical and emotional symptoms and side effects often experienced by patients before, during, and after treatment.

\section{Evidence Acquisition}

In this research the following materials have been studied: main oncology resources pointing to CAM modalities in cancer care, evidence-based articles, most of American and European academic centers which have established integrative oncology clinics, and official and government organizations associated with cancer.

\section{Results}

\subsection{Complementary and Alternative Medicine} (CAM) and Cancer Patients

Complementary therapies have an increasingly important role in the control of symptoms associated with cancer and cancer treatment.

Referring national researches in 2007 , generally, $38 \%$ of adults and $12 \%$ of children use Complementary and Alternative Medicine in United States $(1,2)$. Also, researches issued in 1999 in case of cancer patients show that 25\% to $83 \%$ of them have used complementary medicine in

Copyright (C) 2015, Iranian Society of Clinical Oncology. This is an open-access article distributed under the terms of the Creative Commons Attribution-NonCommercial 4.0 International License (http://creativecommons.org/licenses/by-nc/4.0/) which permits copy and redistribute the material just in noncommercial usages, provided the original work is properly cited. 
different stages of diagnosis on which geographic location and type of cancer was effective $(3,4)$. Recent studies indicate that employing complementary medicine for children with cancer has changed from $31 \%$ to $92 \%$ (4).

Middle East countries have witnessed that CAM has an important role in supportive cancer care and is often used in association with traditional medicine.

There has been a movement over the last 20 years to include complementary medicine in Western biomedicine mainstream practices. Varying degrees of success have been reported but for the discipline of oncology, complementary medicine is now being taught in the public university system to a PhD level as well as the public demand for their medical doctors to communicate with their complementary medicine practitioners. Medical oncology specialists are now open to a dialogue with their complementary medicine counterparts.

In a study in Canada a series of in-depth qualitative interviews with various oncology health professionals recruited from cancer agencies, hospitals, integrative clinics, and private practice settings were reviewed and findings demonstrated two main strategies used by oncologist to create a more integrative approach for cancer patients: acting as an integrative care guide, and cooperating with other health professionals.

Also, studies in Western countries show that educated society with higher level of education and income make more use of complementary medicine $(5,6)$. It is more prevalent to use complementary medicine in young women who have background of surgery, chemotherapy and using complementary medicine (7).

Cancer survivors withstand a wide range of side effects and unwelcome complications during and following completion of treatment, and some of these symptoms may persist for months and years or even decades. While pharmacologic treatments alleviate some symptoms, they produce some difficult side effects. More complementary modalities are noninvasive, inexpensive, and useful in reducing symptoms and improving quality of life. Some high quality scientific research has produced evidence that acupuncture, massage, music, and mindbody therapies effectively and safely reduce physical and emotional affects. These therapies provide an appropriate risk-benefit ratio and authorize cancer care professionals to help manage their own care.

Many of cancer patients experience fatigue, pain, anxiety, and mood suffer whereas conventional treatments do not evermore satisfactorily relieve these symptoms.

A multidisciplinary approach in integrative oncology as mind-body modalities and massage therapy can reduce fatigue, anxiety, and chronic pain.

\subsection{Health Care Professionals' Approach to Inte- grative Oncology Foundation}

Using integrative medicine in oncology has its origin in these principal bases: comprehensiveness, specificity, ev- idence-based entity, and safety (8). This method has been established in response to the concept of treatment with all its aspects.

Integrative oncology relates to an emerging conversation between CAM scholars, oncology care professionals, family practitioners, and other health care providers who imagine an expanded and holistic patient-centered approach to oncology care.

Conventional model of cancer treatment including surgery, radiotherapy and chemotherapy in integrative oncology expands to a multi-disciplinary approach involving all types of CAM modalities like traditional systems as Persian and Chinese medicine, acupuncture, yoga, relaxation, sport, massage, dietary and nutritional therapies, herbal medicine, homeopathy, mind-body medicine, shiatsu, and therapeutic touch.

Without a comprehensive evaluation and fulfillment of patients' whole needs, they absolutely feel a remarkable treatment gap. Symptoms like severe pains or nausea are purely physical sings but when they become chronic, they will show mental effects and will affect patient's social and behavioral state, as an example they will lead to irritability, isolation and insomnia-related fatigue.

The patient is much more likely to say all his needs in an extensive treatment plan in which all dimensions including nutrition/regime, physical activity, side-effect control, sleep, fatigue, digestion, and appetite has been considered.

Studies reveal that cancer patients by using CAM methods hope to support their immunity system, soothe their pains, and reduce side effects of cancer and its treatment. Only a few patients use CAM treatments due to inefficacy of conventional treatments, so, their motive for using CAM depends on sense of more control on their health, reduction of side effects and strong believe in natural therapy(9).

Certain that cancer patients report that they desire to be able to consult with their conventional health practitioners, particularly their oncologists, about their CAM use, health professionals who select to accept integrative practices are likely proposing patients much-welcomed support.

\subsection{Conventional Medicine Approach to Integra- tive Medicine in Cancer Treatment}

So far many CAM therapies have been carefully scrutinized and this trend is growing. In 2009 society for integrative oncology issued evidence-based clinical practice guidelines which should be regarded while using complementary therapeutic methods by doctors in cancer treatments. Also, researchers are evaluating those methods of CAM that people use to lower risk of cancer.

Some of the academic centers which specifically work as comprehensive cancer control centers in integrative medicine are listed in the Table 1, also, updated information and confirmed/approved researches are accessible in the following centers (Table 2). 
Table 1. Academic Centers Which Specifically Work as Integrative Oncology Departments

\begin{tabular}{|c|c|}
\hline Location & Academic Centers \\
\hline Arizona & Cancer Treatment Centers of America (10) \\
\hline California & $\begin{array}{c}\text { University of California San Francisco, Osher Center for Integrative Medicine (11). } \\
\text { Simms/Mann-UCLA Center for Integrative Oncology (12) }\end{array}$ \\
\hline Illinois & $\begin{array}{l}\text { The Block Center for Integrative Cancer Treatment (13). Cancer Treatment Centers of } \\
\text { America (10) }\end{array}$ \\
\hline Maryland & Johns Hopkins Center for Complementary and Alternative Medicine (14) \\
\hline Massachusetts & Dana Farber Cancer Institute, Leonard P. Zakim Center for Integrative Therapies (15) \\
\hline Minnesota & Mayo Clinic's Complementary and Integrative Medicine Program (16) \\
\hline New York & Memorial Sloan Kettering Cancer Center, Integrative Medicine Service (17) \\
\hline Oklahoma & Cancer Treatment Centers of America (10) \\
\hline Pennsylvania & Cancer Treatment Centers of America (10) \\
\hline Texas & The University of Texas MD Anderson Cancer Center, Integrative Medicine Program (18) \\
\hline MD Anderson Cancer Center & http://www.mdanderson.org (19) \\
\hline The Society for Integrative Oncology & http://www.integrativeonc.org (20) \\
\hline
\end{tabular}

Table 2. Some Centers for Access Updated Information and Confirmed/Approved Researches

\begin{tabular}{|c|c|c|}
\hline Center & Type of Activity & Website \\
\hline NCCAM clearinghouse & $\begin{array}{l}\text { The NCCAM Clearinghouse provides information on CAM and NCCAM, } \\
\text { including publications and searches of Federal databases of scientific } \\
\text { and medical literature. The Clearinghouse does not provide medical } \\
\text { advice, treatment recommendations, or referrals to practitioners. }\end{array}$ & nccam.nih.gov \\
\hline National Cancer Institute & $\begin{array}{l}\text { The National Cancer Institute is the Federal Government's lead agency } \\
\text { for cancer research. The National Cancer Institute's Cancer Information } \\
\text { Service provides comprehensive information about cancer. The National } \\
\text { Cancer Institute's Office of Cancer Complementary and Alternative } \\
\text { Medicine coordinates and enhances the National Cancer Institute's } \\
\text { activities in CAM research. }\end{array}$ & www.cancer.gov \\
\hline PubMed $₫$ & $\begin{array}{l}\text { A service of the National Library of Medicine (NLM), PubMed® contains } \\
\text { publication information and (in most cases) brief summaries of articles } \\
\text { from scientific and medical journals. CAM on PubMed®, developed } \\
\text { jointly by NCCAM and NLM, is a subset of the PubMed system and focuses } \\
\text { on the topic of CAM. }\end{array}$ & $\begin{array}{l}\text { www.ncbi.nlm.nih. } \\
\text { gov/sites/entrez CAM } \\
\text { on PubMed@: nccam. } \\
\text { nih.gov/research/ } \\
\text { camonpubmed/ }\end{array}$ \\
\hline
\end{tabular}

Table 3. Some Symptoms and Disorders are More Focused in Integrative Oncology Centers

\begin{tabular}{lr}
\hline Filed & Symptoms and Disorders \\
\hline Mental and nervous system & Stress, Anxiety \& Depression; Neuropathy; Sleeping Problems \& Insomnia \\
Gastrointestinal system & Poor Appetite \& Weight Loss; Nausea \& Vomiting; Constipation; Diarrhea; Taste Change; \\
Other systems & Difficulty Swallowing; Mouth Sores; Dry Mouth \\
General symptoms & Shortness of Breath; Vaginal Dryness \& Pain \\
\hline
\end{tabular}

The rapeutic methods used in these centers are based on following principals:
1. Psychological Support
2. Mind-Body Approaches
3. Groups and Counseling
4. Nutrition, Supplements
5. Complementary Medicine
6. Psychiatry and Oncology
7. Insights Into Cancer

The most common CAM modalities used in these centers are as follows:

traditional systems as Persian medicine, Chinese medicine, ayurveda; acupuncture; massage; spirituality; aromatherapy; art therapy; biofeedback; meditation; music therapy; tai chi; yoga; botanical medicine; breath work; Chinese herbs; chiropractic; clinical hypnosis; craniosacral therapy; creative therapies; cupping; dermal friction; dietary therapies; food as medicine; healing envi- 
ronment; homeopathy; imagery; mind-body therapies; mindful movement; moxibustion; naturopathy; osteopathy; prayer; qigong; reflexology; reiki; shamanism; shiatsu; social support; therapeutic touch.

\section{Discussion}

There is an increasing recognition in health care systems, especially in oncology, of the importance of maintaining or improving patients' quality of life all over the disease course (21).

The core principles of this modality consist of individualization, holism, dynamism, synergism, and collaboration in mainstream cancer care.

The patient in this method can be guided to make effective decisions about the most helpful integrative therapies throughout their treatment program and beyond. It is essential to patient care team to pay enough attention to safety, standardization, and quality of therapeutic methods and improper drug interactions, simultaneous use of antioxidants with chemotherapy or radiotherapy, appropriate use of phytoestrogens, focus on metabolic interactions, prevention of hepatotoxicity and nephrotoxicity, and in case of herbal medicine factors like their direct biological effect on cancer, should be considered.

Care for quality of life makes a connection between the patient and patient care team. This means that both treatment and patient's quality of life are of high importance for patient care team.

Cancer patients with lower quality of life were more likely to terminate therapy so this should be as an alarm to oncologist the risk for not completing therapy. Complementary methods have played a significant role in this situation for enhancing quality of life, reduced severity of symptoms and side effects, and developed general wellbeing in patients (22).

Integrative oncology can be negotiated as a new considering and approach to better management of cancer and cancer patient to improve quality of life and treatment results.

\section{References}

1. Bell RM. A review of complementary and alternative medicine practices among cancer survivors. Clin J Oncol Nurs. 2010;14(3):365-70.

2. U.S. Department of Health and Human Services . National Institutes of Health; 2009. Available from: http:|/newsinhealth.nih. gov.
3. Richardson MA, Sanders T, Palmer JL, Greisinger A, Singletary SE. Complementary/alternative medicine use in a comprehensive cancer center and the implications for oncology. J Clin Oncol. 2000;18(13):2505-14.

4. Gow CH, Chang YL, Hsu YC, Tsai MF, Wu CT, Yu CJ, et al. Comparison of epidermal growth factor receptor mutations between primary and corresponding metastatic tumors in tyrosine kinase inhibitor-naive non-small-cell lung cancer. Ann Oncol. 2009;20(4):696-702.

5. Räsänen C. Factors influencing the use of complementary and alternative medicine among cancer patients. Salo: Turku University of Applied Sciences; 2010.

6. Tascilar M, de Jong FA, Verweij J, Mathijssen RH. Complementary and alternative medicine during cancer treatment: beyond innocence. Oncologist. 2006;11(7):732-41.

7. Wyatt G, Sikorskii A, Wills CE, Su H. Complementary and alternative medicine use, spending, and quality of life in early stage breast cancer. Nurs Res. 2010;59(1):58-66.

8. National Center for Complementary and Alternative Medicine. Exploring the Science of Complementary and Alternative Medicine. USA: U.S Department of health and human services; 2011-2015.

9. Ulbricht C, Cohen L, Lee R. Complementary, Alternative, and Integrative Therapies in Cancer Care. In: DeVita V, Hellman S, Lawrence TS, Rosenberg SA, editors. DeVita, Hellman, Rosenberg's Cancer. Principles \& Practice of Oncology. 9 ed. United States: Wolters Kluwer/Lippincott Williams \& Wilkins Health; 2011.

10. Cancer Treatment Centers of America. How can genomic testing help patients now?. Available from: http://www.cancercenter.com.

11. University of California SF. Osher Center For Integrative Medicine. Available from: http://www.osher.ucsf.edu/.

12. The Simms/Mann - UCLA Center for Integrative Oncology. Available from: http://www.simmsmanncenter.ucla.edu/.

13. Block Center for Integrative Cancer Treatment. Available from: http://www.blockmd.com/.

14. Johns Hopkins Medicine. GIM Program in Integrative Medicine Available from: http://www.hopkinsmedicine.org/cam/.

15. Dana-Farber Cancer Institute. Available from: http://www.danafarber.org/Research/Departments-and-Centers.aspx.

16. Mayo Clinic Staff. Complementary and Integrative Medicine. Available from: http://www.mayoclinic.org/departments-centers/general-internal-medicine/minnesota/overview/specialty-groups/ complementary-integrative-medicine.

17. Memorial Sloan Kettering Cancer Center. Integrative Medicine. Available from: http://www.mskcc.org/cancer-care/integrativemedicine.

18. University of Texas: MD Anderson Cancer Center. Integrative Medicine Program. Available from: http://www.mdanderson.org/ education-and-research/departments-programs-and-labs/programs-centers-institutes/integrative-medicine-program/index. html.

19. University of Texas: MD Anderson Cancer Center. Patient and Can cer Information. Available from: http://www.mdanderson.org/.

20. Society for Integrative Oncology. Clinical Practice Guidelines. Available from: http://www.integrativeonc.org.

21. Jacobsen PB, Davis K, Cella D. Assessing quality of life in research and clinical practice. Oncology (Williston Park). 2002;16(9 Supp 10):133-9.

22. Beuth J, Moss RW, Abel U. Complementary oncology: adjunctive methods in the treatment of cancer. Thieme; 2005. 